\title{
Nonunion of anterior inferior iliac spine avulsion fracture
}

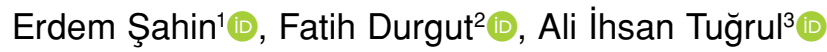 \\ 1Department of Orthopedics and Traumatology, Erzurum Regional Training and Research Hospital, Erzurum, Turkey \\ ${ }^{2}$ Department of Orthopedics and Traumatology, Dicle University Faculty of Medicine, Diyarbakır, Turkey \\ ${ }^{3}$ Department of Orthopedics and Traumatology, Beyhekim Training and Research Hospital, Konya, Turkey
}

Avulsion fractures of the pelvis are usually observed in the skeletally immature population, particularly those who are involved in sports. Sprint running, sudden accelerating, and decelerating are the most common activities leading to avulsion fracture. This condition is more common in males than in females. ${ }^{[1]}$ The occurrence mechanism of these fractures is sudden and strong contraction of the muscle attached to the apophysis. ${ }^{[2]}$

Avulsion fractures of the anterior inferior iliac spine (AIIS) are less frequent than other pelvic avulsions with an incidence of 14.8 to $22.1 \%$, possibly related to earlier apophyseal closure than the others. ${ }^{[3]}$ Anterior inferior iliac spine avulsion fractures occur due to the pull of rectus femoris muscle during forceful extension of the hip. These patients are presented with complaints of groin pain, pain during hip joint movements and

Received: January 05, 2022

Accepted: January 14, 2022

Published online: February 10, 2022

Correspondence: Erdem Şahin, MD. Erzurum Bölge Eğitim ve Araştırma Hastanesi, Ortopedi ve Travmatoloji Kliniği,

25240 Yakutiye, Erzurum, Türkiye.

E-mail: dr.erdemsahin@gmail.com

Doi: $10.52312 /$ jdrscr. 2022.58

Citation: Şahin E, Durgut F, Tuğrul Al. Nonunion of anterior inferior iliac spine avulsion fracture. Jt Dis Relat Surg Case Rep 2022;1(2):55-58.

C2022 All right reserved by the Turkish Joint Diseases Foundation

This is an open access article under the terms of the Creative Commons Attribution-NonCommercial License, which permits use, distribution and reproduction in any medium, provided the original work is properly cited and is not used for commercial purposes (http://creativecommons.org/licenses/by-nc/4.0/).

https://www.casereportsjointdrs.org

\section{ABSTRACT}

Avulsion fractures of the pelvis are usually observed in skeletally immature patients, involved in sports. Sprint running and sudden accelerating and decelerating activities are the most common mechanism for these fractures. We present an adult patient diagnosed with avulsion fracture of the anterior inferior iliac spine, who experienced a nonunion after conservative treatment. The nonunion was treated surgically, 11 months after the fracture. The patient was not allowed to put any weight on the affected extremity and to extend the hip for the first two months. As of the third month, the patient started hip extension and weight bearing gradually with crutches. The patient was free of symptoms six months after the operation and radiographs showed complete healing of the fracture.

Keywords: Anterior inferior iliac spine, avulsion fracture, nonunion.

limping. Avulsions may often go undiagnosed in the emergency setting, and patients may receive a conservative treatment with the diagnosis of soft tissue trauma. However, avulsion fractures of AIIS can be diagnosed with medical history and thorough investigation of radiographs.

Fractures of the AIIS is uncommon in adults and, as these fractures are more common in the skeletally immature, such fractures may go undiagnosed. In this article, we present an adult patient initially misdiagnosed as soft tissue trauma to the groin, and received conservative treatment. The patient was diagnosed with AIIS avulsion fracture nonunion at five months after the trauma and treated surgically.

\section{CASE REPORT}

A 23-year-old male patient had no known disease, history of surgery was admitted to the emergency room (ER) with complaints of pain in the right groin and limping that developed after kicking the ball during an amateur football match. He was diagnosed 


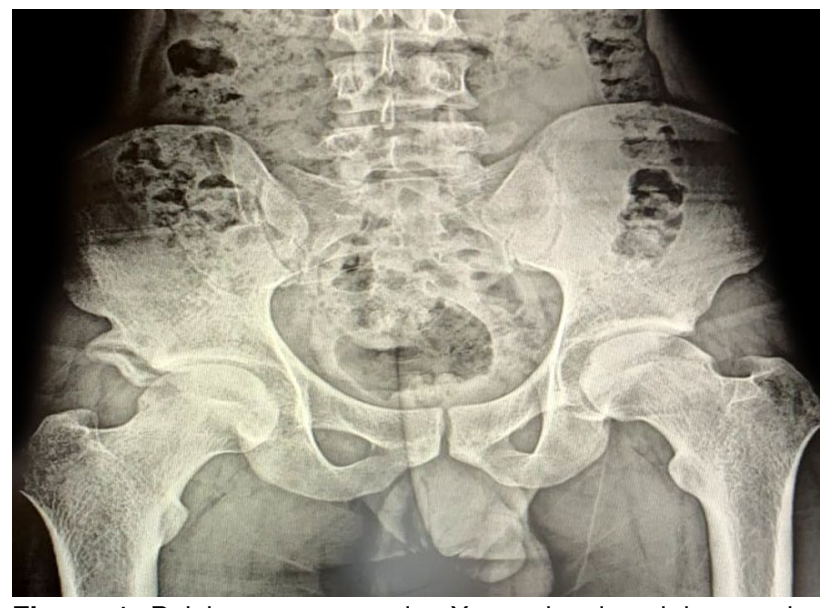

Figure 1. Pelvis anteroposterior X-ray showing right anterior inferior iliac spine avulsion fracture five months after the injury.

with soft tissue injury and received conservative treatment.

Five months after the injury, the patient was admitted to the outpatient clinic with complaints of pain during hip movements and difficulty running. Physical examination revealed limited range of motion of the right hip compared to the healthy side. Flexion and abduction were painful. In
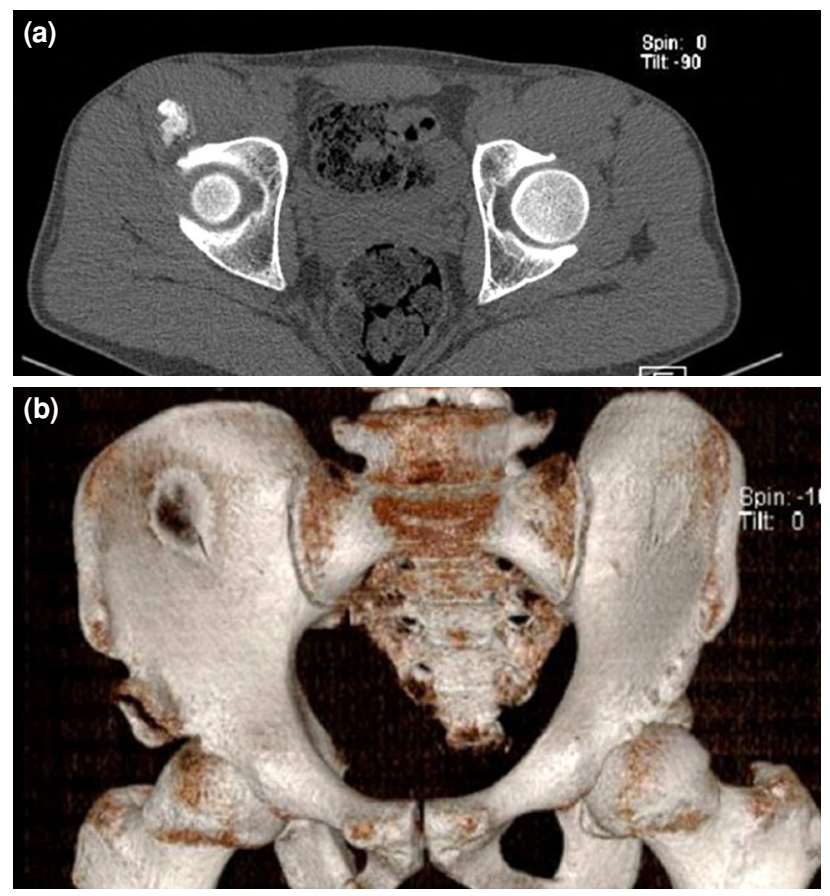

Figure 2. Computed tomography scan axial view (a) and threedimensional reconstruction (b) showing nonunion five months after the injury. addition, adduction and internal rotation provoked pain, suggesting a femoroacetabular impingement. Anteroposterior pelvis radiograph (Figure 1) and the computed tomography scan (Figure 2) revealed that the patient had an avulsion type fracture in the right AIIS that was in the process of healing. Based on the assumption that the union of the fracture was delayed, it was decided to continue conservative treatment.

The patient was admitted to the outpatient clinic with similar complaints, 11 months after the trauma. Although the patient did not smoke, a nonunion was diagnosed (Figure 3). Surgical treatment for the nonunion was planned. A SmithPetersen was used to approach and expose the AIIS (Figure 4). The rectus femoris muscle was identified to be intact. Callus was removed and the fragment was mobilized. Following appropriate reduction of the fragment to the pelvis under fluoroscopy guidance fracture was fixed with two 4.5-mm cancellous screws after repositioning (Figure 5). The patient was not allowed to put any weight on the affected extremity and to extend the hip for the first two months. As of the third month, the patient started hip extension and weight bearing gradually with crutches. Six months after the operation, the patient was free of symptoms and radiographs showed complete healing of the fracture (Figure 6).

The patient was informed that data from the case would be submitted for publication and gave his consent.

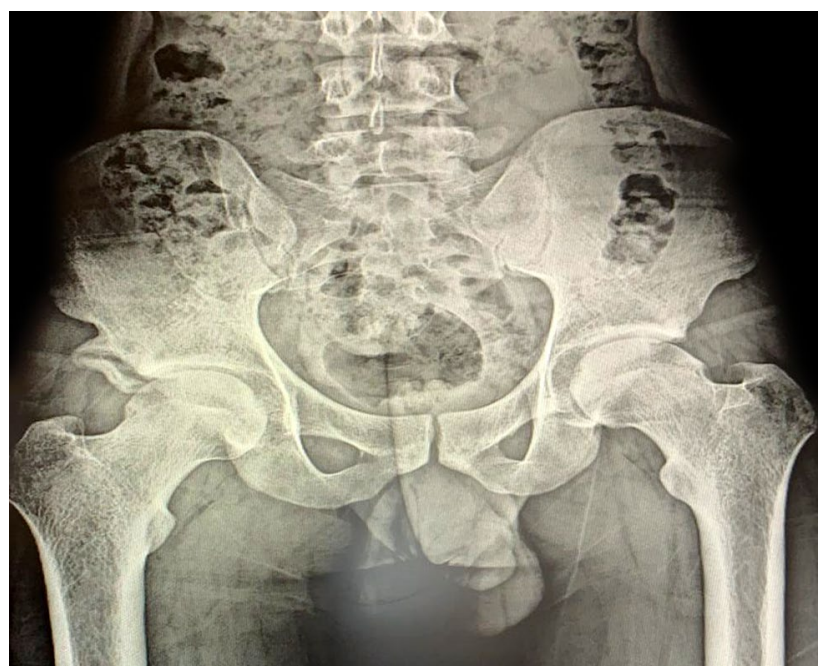

Figure 3. Pelvis anteroposterior X-ray showing a right anterior inferior iliac spine avulsion fracture 11 months after the injury. 

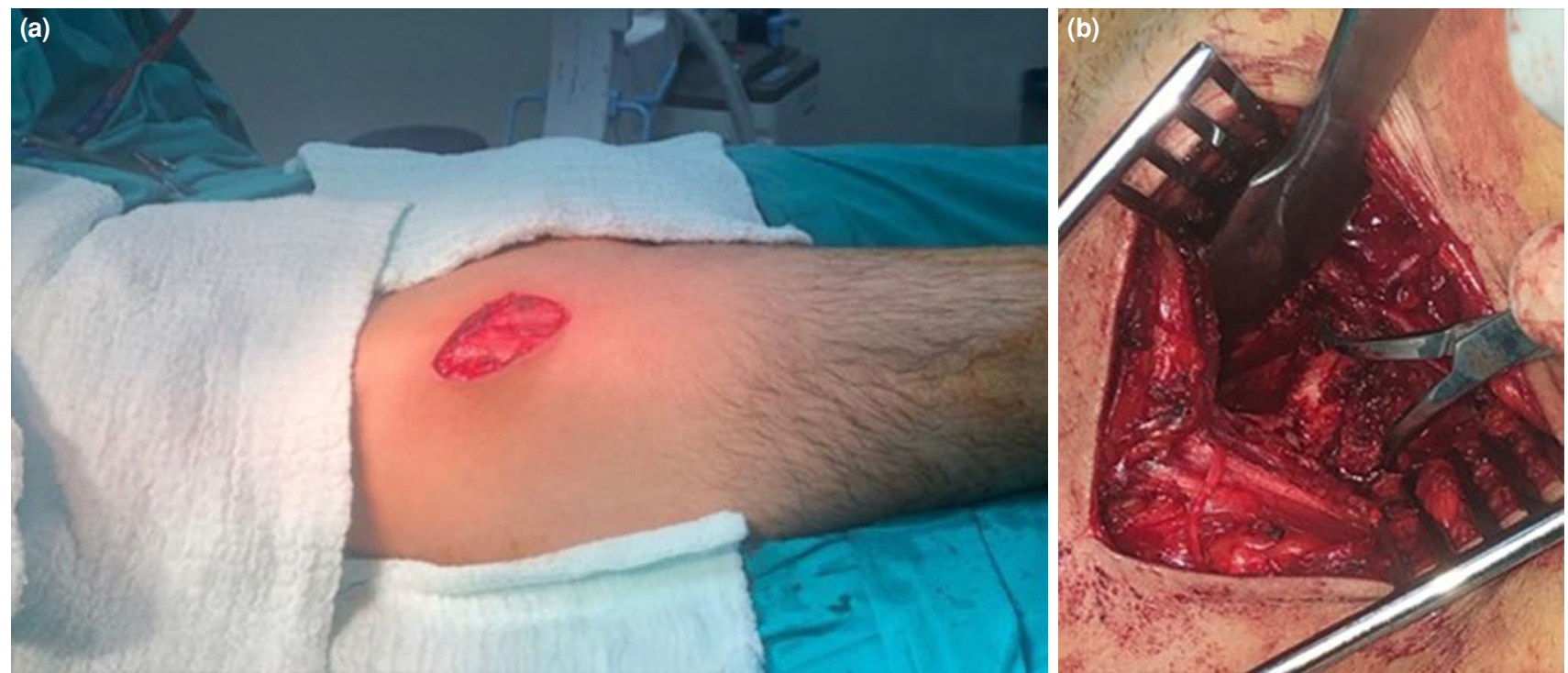

Figure 4. (a) Surgical incision (anterior approach) and (b) appearance of avulsion fracture with rectus femoris insertion.
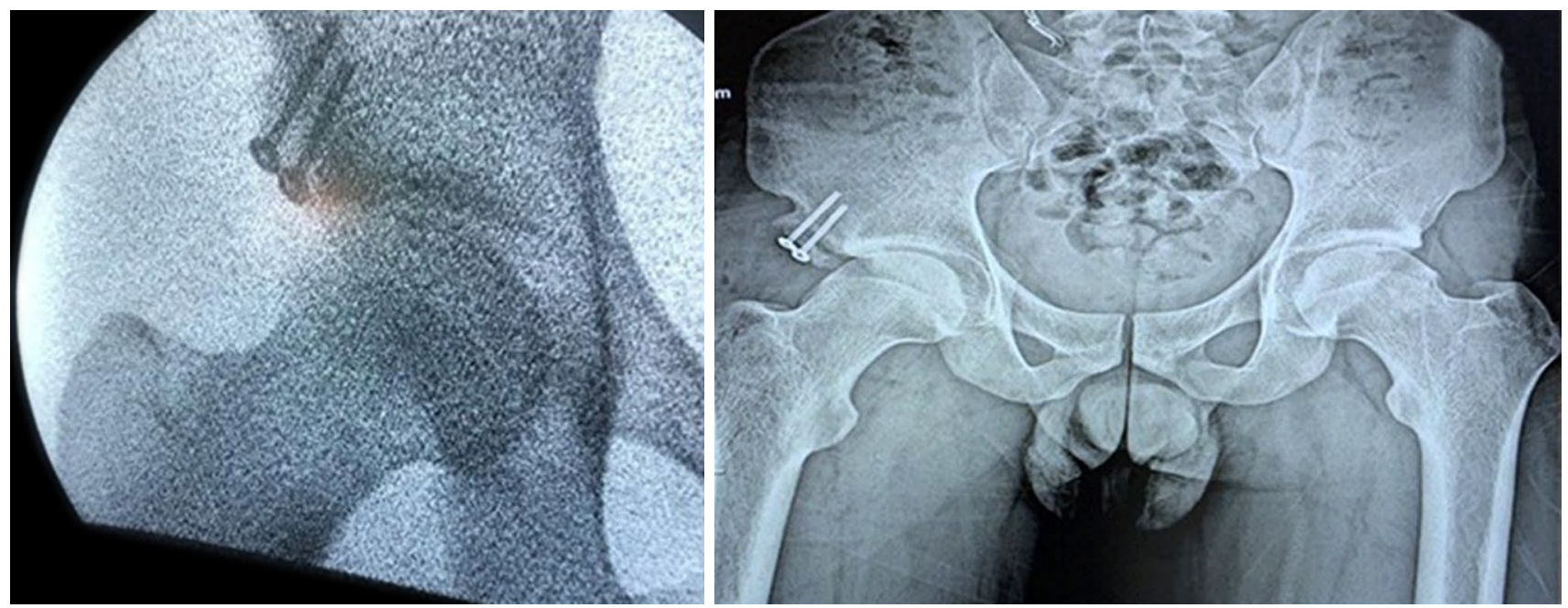

Figure 5. Post-fixation fluoroscopy image and early postoperative radiograph.

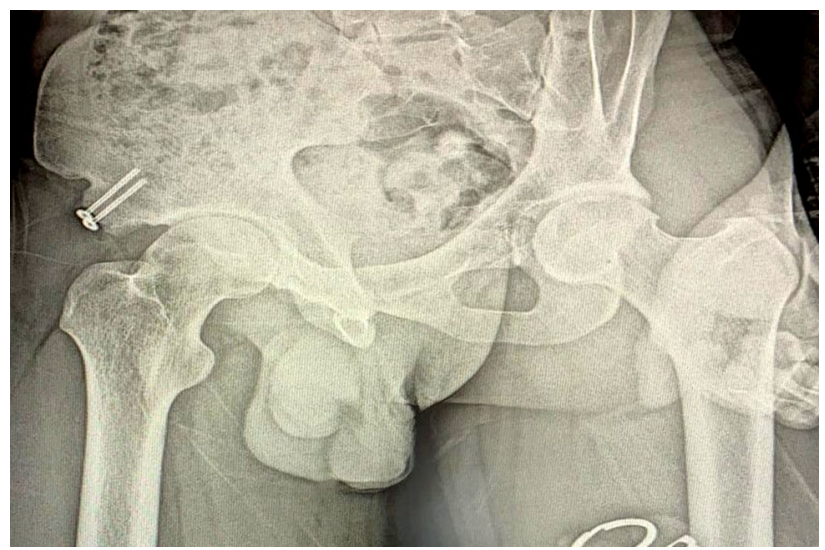

Figure 6. Postoperative radiograph at six months showing healing.

\section{DISCUSSION}

Anterior inferior iliac spine avulsion fractures are uncommon conditions which occur after a sudden, uncoordinated, severe contraction of the rectus femoris muscle. After acute pelvis avulsion fracture, patients typically describe hearing a "pop" sound. Subsequently, severe pain and muscle dysfunction develop. It is usually seen in sportive and active individuals in adolescence. This injury is rare in adults. Gamradt et al. ${ }^{[4]}$ reported that injuries of $11^{\text {th }}$ National Football League athletes who developed AIIS avulsion fractures between 1997 and 2006 occurred in various positions, and all patients were treated conservatively. 
The radiological image of an AIIS avulsion fracture is usually in the shape of a crescent or a triangle. Fracture often appears minimally inferiorly displaced. Computed tomography and magnetic resonance imaging can also be used in diagnosis.

These injuries are usually treated conservatively and sufficient healing and early return to sports can be expected. ${ }^{[1,5]}$ However, some authors recommend surgery based on the amount of displacement of the avulsed segment. ${ }^{[6]}$ The most common complications in patients undergoing conservative treatment are formation of exocytosis, absence of union, and persistent pain. ${ }^{[7]}$ Open reduction and internal fixation are usually indicated in cases with fragment displacement of more than $3 \mathrm{~cm}$, nonunion and the need for short return to activity ${ }^{[8]}$ In addition, there are some studies showing that these cases are treated arthroscopically in the literature. ${ }^{[9,10]}$

Radiographs of the patient had osteoarthritis findings; however, the patient did never had a symptom before. Although not mentioned in the literature, early osteoarthritis and mixed type femoral acetabular impingement findings in both hips of the case we presented were though to predispose for AIIS avulsion fracture.

In conclusion, cases of AIIS fracture in skeletally mature patients are uncommon; therefore, they can be treated inadequately due to misdiagnosis. Although conservative treatment is typically the first option, nonunion may occur which necessitates a surgical intervention.

\section{Declaration of conflicting interests}

The authors declared no conflicts of interest with respect to the authorship and/or publication of this article.

\section{Funding}

The authors received no financial support for the research and/or authorship of this article.

\section{REFERENCES}

1. Rossi F, Dragoni S. Acute avulsion fractures of the pelvis in adolescent competitive athletes: Prevalence, location and sports distribution of 203 cases collected. Skeletal Radiol 2001;30:127-31.

2. Gomez JE. Bilateral anterior inferior iliac spine avulsion fractures. Med Sci Sports Exerc 1996;28:161-4.

3. Yildiz C, Yildiz Y, Ozdemir MT, Green D, Aydin T. Sequential avulsion of the anterior inferior iliac spine in an adolescent long jumper. Br J Sports Med 2005;39:e31.

4. Gamradt SC, Brophy RH, Barnes R, Warren RF, Thomas Byrd JW, Kelly BT. Nonoperative treatment for proximal avulsion of the rectus femoris in professional American football. Am J Sports Med 2009;37:1370-4.

5. Sundar M, Carty H. Avulsion fractures of the pelvis in children: a report of 32 fractures and their outcome. Skeletal Radiol 1994;23:85-90.

6. DePalma AF, Silberstein CE. Avulsion fracture of the ischial tuberosity in siblings. A report of 2 cases. Clin Orthop Relat Res 1965;38:120-2.

7. Irving $\mathrm{MH}$. Exostosis formation after traumatic avulsion of the anterior inferior iliac spine.Report of two cases. J Bone Joint Surg Br. 1964;46:720-2.

8. Yildiz C, Aydin T, Yildiz Y, Kalyon TA, Basbozkurt M. Anterior inferior iliac spine apophyseal avulsion fracture. J South Orthop Assoc 2003;12:38-40.

9. Novais EN, Riederer MF, Provance AJ. Anterior inferior iliac spine deformity as a cause for extra-articular hip impingement in young athletes after an avulsion fracture: A case report. Sports Health 2018;10:272-6.

10. Nakano N, Lisenda L, Khanduja V. Arthroscopic excision of heterotopic ossification in the rectus femoris muscle causing extra-articular anterior hip impingement. SICOT J 2018;4:41. 